\title{
Analysis of hot spell characteristics in the Greek region
}

\author{
B. D. Katsoulis, N. Hatzianastassiou* \\ Laboratory of Meteorology, Department of Physics, University of Ioannina, 45110 Ioannina, Greece
}

\begin{abstract}
In the present study, hot spell conditions over the Greek region during the warm period (June to September) were examined by using daily maximum temperature data from 16 meteorological stations of the Hellenic National Meteorological Service (HNMS) and a combined deterministicstochastic model. The results show that daily maximum temperatures can be studied as a mixture of deterministic and stochastic components, whereas the properties of hot spells can be adequately described with statistical distributions. Trends and the geographical and temporal distribution of hot spells at the surface were investigated by linear regression, Fourier analysis and statistical distributions. Partial duration series of hot spells, fitted with Poisson, Gauss and exponential distributions, provide information on their frequency, timing, magnitude and geographical distribution. The most frequent hot spells are found over southern parts of inland Greece, as well as over the northern mainland, while less frequent events occur along the coastal belt of the Greek Peninsula and in the Aegean Islands. Hot spells are more frequent at inland than in marine areas, and occur from June to September. Statistical analysis of synoptic weather conditions that favour the development of hot spells shows that such events are most probable over Greece when (1) a persistent Azores anticyclone appears over North Africa and extends ridges of high pressure towards the NE Mediterranean, and (2) when western and central European anticyclones extend towards the region.
\end{abstract}

KEY WORDS: Synoptic weather conditions $\cdot$ Hot spell $\cdot$ Frequency $\cdot$ Timing $\cdot$ Magnitude $\cdot$ Statistical distributions

Resale or republication not permitted without written consent of the publisher

\section{INTRODUCTION}

During recent decades, extremely hot and dry summers have been experienced frequently in southern and western European areas and in other regions of the Northern Hemisphere (Goossens \& Berger 1984, Douguedroit 1987, Gerstengarbe \& Werner 1992, Palutikof et al. 1996, Anagnostopoulou et al. 2003, Beniston 2004). Various studies have described the characteristics and impacts of these extreme temperature events (Degaetano 1996, Heino et al. 1999, Karl \& Easterling 1999, Easterling et al. 2000). However, most analyses of extreme weather conditions in Europe are local or national in scope, making it difficult to obtain a continental overview of associated trends (e.g. Macchiato et al. 1993, Domonkos 1998, 2001).
Hot spell conditions can have a devastating impact on the natural environment (e.g. reducing availability of water, triggering forest fires, increasing growth of algae). Variations and trends in hot spells have also received much attention due to their effects on human health (including loss of life), particularly in urban areas, and because they are responsible for increasing agricultural damage and other economic costs (Wagner 1999, McCarthy et al. 2001).

There have been detailed analyses of individual severe events that caused effects on human health and associated hospitalisation rates and, in combination with air pollution, increased mortality, especially in urban areas (e.g. Katsouyanni et al. 1988, Giles \& Balafoutis 1990, Giles et al. 1990, Matzarakis \& Mayer 1991, Changnon et al. 1996). 
The areas most severely affected by hot spells are in Mediterranean regions threatened by desertification. Various scenarios suggest that extreme weather conditions around the Mediterranean Sea will affect climate-related resources. The implications of changes in the characteristics of hot spells and their impacts extend beyond the sectors of agriculture and water, to industry, settlements, coastal zones, transport, tourism, health and insurance policies (Balling et al. 1990, Changnon et al. 1996, Karl \& Knight 1997, McCarthy et al. 2001). Extreme temperature events have been studied by many investigators in the broader Mediterranean region, and more generally in other regions of Europe as well as of other continents (e.g. Mearns et al. 1984, Katz \& Brown 1992, Corte-Real et al. 1995, Reddaway \& Bigg 1996, Heino et al. 1999, Karl \& Easterling 1999, Maheras et al. 1999, Easterling et al. 2000, Xoplaki et al. 2003). Extended hot spells appear to become more frequent in the Greek region, though they are largely unquantified. In particular, Greece is likely to be adversely affected by increasing fire hazards in forests and increasing heat stress to humans, crops and livestock. Therefore, Greece appears to be quite vulnerable to exceptional hot weather conditions.

Studies of extreme temperatures in the Greek region have been performed by Repapis (1975), Flocas \& Angouridakis (1979), Flocas (1981), Katsoulis (1987), Giles \& Balafoutis (1990), Matzarakis \& Mayer (1991), among others. These studies were based on simple statistical treatment of maximum temperatures in combination with analyses and case studies of synoptic conditions that caused the hot spells and heat waves, or they examined the phenomenon from the viewpoint of bioclimatology.

Despite their importance, relatively little is known about the climatic behaviour of hot spells. Therefore, their analysis in a region such as Greece is of considerable importance to many activities and climatic characteristics. The investigation of hot spells and the relevant weather types that favour their occurrence, frequency, timing, intensity, along with the distribution of these events constitute an important field of study.

In general, a hot spell is defined as a time period during which the maximum daily temperatures are higher than the mean maximum seasonal levels; other conditions must be satisfied as well (Macchiato et al. 1993, Henderson \& Muller 1997, Folland et al. 1999, McCarthy et al. 2001). Similarly, a heat wave is defined as an extended period of unusually high atmosphererelated heat stress, which causes temporary modifications in the way of living and which may have adverse health consequences for the vulnerable groups of human population (Matzarakis \& Mayer 1991, 1997, Robinson 2001). In this study, a hot spell is defined as the atmospheric condition during which the mean daily maximum air temperatures exceed a predetermined 'normal' level (here: $\mathrm{T}_{\max }>30^{\circ} \mathrm{C}$ ), for at least $2 \mathrm{~d}$. The temperature level can set by the user, depending on the focus of the study (see Section 3.1).

\section{STUDY REGION AND DATA}

The present analysis of hot spells in Greece follows the study of cold spells by Pappas et al. (2004), who describe the study region, dataset, definitions and methodology in greater detail.

\subsection{Physicogeographical and climatological characteristics}

The Greek region, which is characterised by great irregularity of land and water distribution, and by marked contrasts in topography, has a variety of climatic deviations from the general pattern of the Mediterranean climate. Greece can be divided into 3 climatic entities: (1) eastern peninsula, (2) western peninsula, and (3) islands and the SE coastal regions of the Aegean Sea and Crete, where the climate is more temperate (Furlan 1977). The region is a transitional area between North Africa (semi-arid zone of the subtropical high pressure region) and SE Europe (temperate region influenced by westerly air flow). The range of summer mean maximum temperatures in the region is $11^{\circ} \mathrm{C}$. Most of the Greek region belongs to Köppen's Mediterranean type Csa, but types Csb, Cfa and Cfb also appear.

The major orographical factors influencing the Greek climate are the barrier effect of Balkan and Greek mountain ranges (rising to over $2500 \mathrm{~m}$ ) and the destabilizing effect of the eastern Mediterranean Sea. Other factors of influence are latitude, longitude, altitude, topography, land-sea interactions, and local mesoscale and small-scale processes. The semienclosed Adriatic and Aegean Seas, which represent important sources of energy and moisture, together with the complex coastal and land topography, strongly affect local patterns of climate.

\subsection{Dataset}

The analysis is based on data series for 16 meteorological stations (Fig. 1) of the Hellenic National Meteorological Service (HNMS). Here, daily maximum temperature is defined as the highest temperature recorded during a day at a station. The average interval of the temperature data used was $1 \mathrm{~h}$. Unreliable data were excluded. A 31 yr series (1967-1997) of daily max- 


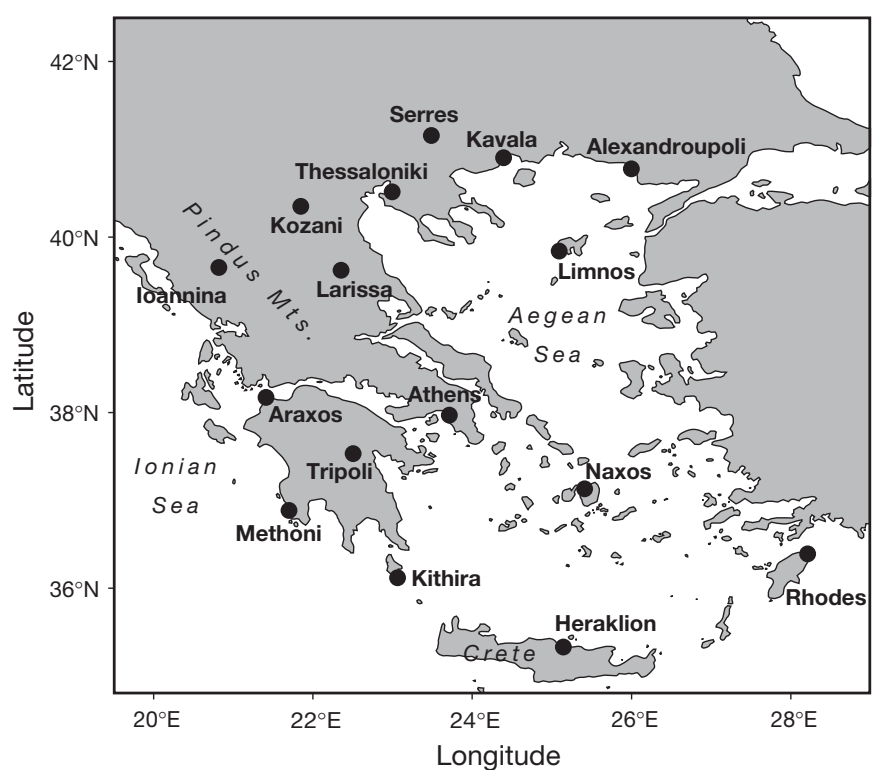

Fig. 1. The broader region for the study of hot spells and the location of stations (cf. Table 1 in Pappas et al. 2004)

imum temperatures from 12 stations was used, as well as data for different time periods (13 to 16 yr) from 4 stations; the latitude, longitude, altitude and duration of the datasets are given in Pappas et al. (2004, their Table 1). The station records were quality controlled by standard methods (WMO 1986). Synoptic conditions that favour the development of hot spells were determined and classified using synoptic surface and upper level maps taken from the HNMS and the German Meteorological Service (GMS, Täglicher Wetterbericht).

\section{DEFINITIONS AND METHODS}

\subsection{Definitions}

A proper tool to analyse abnormal meteorological events is 'crossing theory' (theory of runs). Strictly speaking, the term 'crossing theory' is used for continuous series, whereas for discrete series the term 'run theory' is often used. In the context of crossing theory, hot spells are referred to as runs. A run is defined as a sequence of observations of the same type (e.g. above a given level) preceded and followed by 1 or more observations of a different type (Cramer \& Leadbetter 1967). Various statistics are associated with runs, but in this study we deal only with the run length. This is the time period (days) during which the maximum temperature rises above a given level. The run length assumes only integer values; e.g. $n(t)=2$ means that the hot spell event was 2 d long). Such events can be modelled by appropriately mixed deterministicstochastic processes (Leboutillier \& Waylen 1988).

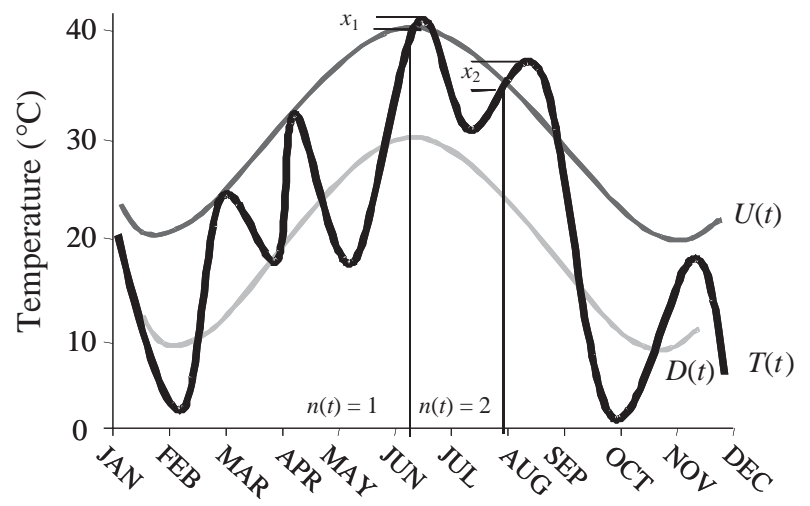

Fig. 2. Hypothetical thermograph of daily maximum temperatures $T(t)$, showing the variables that determine a hot spell. $D(t)$ is the expected long-term daily maximum temperature and $U(t)$ is the cut-off temperature level (as in Fig. 1 of LeBoutillier \& Waylen 1988); $n(\mathrm{t})$ is the number and $x$ is the magnitude of the hot spell

The characteristics of hot spells during which the recorded individual daily maximum temperatures $T(t)$ are higher by a predetermined value than the expected daily maximum temperature, $D(t)$, can be examined by using specific variables (Fig. 2). The cutoff level, $U(t)$, above which the occurrences of daily maximum temperatures indicate the existence of hot spells, can be defined either on the basis of practical aspects, or arbitrarily. The period during which the temperatures $T(t)$ are higher than $U(t)$, forms a hot spell, and the times of upcrossings represent the series of the timing of these events, $\tau_{1}, \tau_{2}, \ldots, \tau_{n}$. Let us suppose that $n(t)=0,1,2, \ldots$, is the number of hot spells for a period up to day $t$, where $1 \leq t \leq 365$. For each of the $n(t)$ hot spells, there exists a starting date, i.e. upcrossing $U(t)$ of the spell, $\tau$, and an ending date, i.e. downcrossing $U(t), \tau+\Delta t$, as well as a highest temperature, $x_{1}$ above the predetermined cut-off level. The characteristics of both the expected daily temperatures and the probability of deviations from the normal values, have periodic and harmonic variations.

The magnitude of a hot spell, $x_{\mathrm{i}}$, is defined as the maximum absolute difference between $T(t)$ and $U(t)$, during the hot spell, i.e. $x_{1}=\max |T(t)-U(t)|$ for $\tau \leq t \leq$ $\tau+\Delta t$ and it gives the series of $x_{1}, x_{2}, \ldots, x_{n}$.

To obtain reliable results, the cut-off level must be selected at a temperature level that ensures the largest number of statistically independent hot spells; the results can be then extrapolated to any warmer temperature level. There may be 2 aspects for the establishment of thresholds for hot spells:

(1) Exceeding fixed absolute values. Given that in most Greek areas, temperatures during a hot spell are higher than $30^{\circ} \mathrm{C}$, the value of $30^{\circ} \mathrm{C}$, is the chosen temperature cut-off level $U(t)$ on each day $t$. 
(2) Deviation from normal. The mean daily maximum temperatures are lower in northern than in southern stations. To investigate this effect, other truncation levels were also tested. Examination of the number of crossings per period revealed that a level $U^{\prime}(t)$ of $10^{\circ} \mathrm{C}$ above the mean value, yields the maximum number of independent events and yet meets the Poisson assumption of stochastic process. The results are discussed in Section 4.

\subsection{Methodology}

The method applied in this study consists of a combined deterministic and stochastic model previously used for cold spells (LeBoutillier \& Waylen 1988, Pappas et al. 2004). The method (1) adopts as decisive factors the long-term tendency and the seasonal periodicity of temperature, represented by linear regression and Fourier analysis, respectively; (2) analyzes the probability of occurrence of hot spells by applying statistical probability distributions (WMO 1983, Ross 1985); (3) investigates the extension of the results of a predetermined cut-off level to higher cut-off levels. The method is described in detail in Pappas et al. (2004). Here, we highlight differences due to the fact that this study is concerned with hot spells, while Pappas et al. (2004) dealt with cold spells. The expected daily maximum temperature, $D(t)$, at day $t$ of the year, is given by a simple harmonic relation, as the sum of the annual mean and a single harmonic term of the annual cycle:

$$
D(t)=\bar{T}_{\max }+A \sin [2 \pi t / 365+\varphi]
$$

where $\bar{T}_{\max }$ is the annual mean daily maximum temperature, $A$ is half of the annual range of daily maximum temperatures, $\varphi$ is the phase angle, and $t$ is the Julian day in a calendar year. Any long-term tendency is assumed to be linear, so $\bar{T}_{\text {max }}$ is represented by the linear equation:

$$
\bar{T}_{\text {max }}=\mathrm{a}+\mathrm{b} \text { (year) }
$$

The small trends revealed by the linear regression of $\bar{T}_{\max }$ against time were subsequently removed from daily records and the parameters of the simple harmonic (1), were calculated over the detrended record of daily maximum temperature by entering Fourier analysis (see Pappas et al. 2004).

The Gauss distribution, which provides a reasonable fit to the $t$-dependence of days of hot spells, it is given by:

$$
G(\tau \leq t)=\int_{t}^{\infty} \frac{1}{\sqrt{2 \pi \sigma}} \mathrm{e}^{-(s-\mu)^{2} / 2 \sigma^{2}} d s
$$

where $s$ is the timing of hot spells. The parameters $\mu$ and $\sigma^{2}$ (mean value and the variance of timing of hot spells) are estimated by the method of moments. The dates of 1 June and 30 September were used as the start and end dates of the study period. The distribution of the absolute maximum daily temperature in a hot spell $(M)$, which is higher than the cut-off level temperature by $x$, is given by the exponential distribution

$$
M(x \geq X)=\mathrm{e}^{-\mathrm{x} / \gamma}
$$

where $x$ is the cut-off temperature and $\gamma$ is the mean magnitude of hot spell events, which is estimated by the method of moments. The equations for the Poisson and exponential distributions that were applied to fit the frequency and magnitude of hot spell events were identical to those in Pappas et al. (2004).

In this study, we determined the periods, tendency, frequency, timing, magnitude and geographical distribution of hot spells. The present study attempts also to investigate the local effects of latitude, longitude and altitude on the temperature characteristics, in terms of parameters of the temperature models. In this way, local tendencies of the characteristics of temperature can be determined and then, interpolations can be made for the regions where meteorological records do not exist.

\section{STATISTICAL ANALYSIS AND RESULTS}

Regional studies have shown an expansion of areas with extreme high temperatures since the mid-1970s (Katz \& Brown 1992, Changnon 1993, Rohli \& Keim 1994, Degaetano 1996, Folland et al. 1999, Karl \& Easterling 1999). It is likely that the frequency of hot spells will also increase along with the general increase in heat waves. This is indicated by some recent extreme hot periods that led to a considerable number of deaths in the human population, such as 1987 in Greece (Katsouyianni et al. 1988), 1995 in the USA (Karl \& Knight 1997) and 2003 in western Europe (Beniston 2004). Although there is no apparent trend in the frequency of hot spells during the last few decades, some climatologists assume that the expected increase in global temperature in the 21st century will increase the probability of hot periods in some regions (Wagner 1999, McCarthy et al. 2001). On the basis of these predictions, we applied linear regression to time series of the warm period mean maximum temperatures. The calculated rate of the mean temperature trend for the warm period of 4 months (June, July, August, September) is $0.003^{\circ} \mathrm{C} \mathrm{yr}^{-1}$. The most pronounced characteristic was the warming at the end of the 1990s, which was found in the time series of almost all stations. The warmest hot spell events were in 1999, especially in August and September. The application of a linear regression of maximum temperature vs. time reveals that 

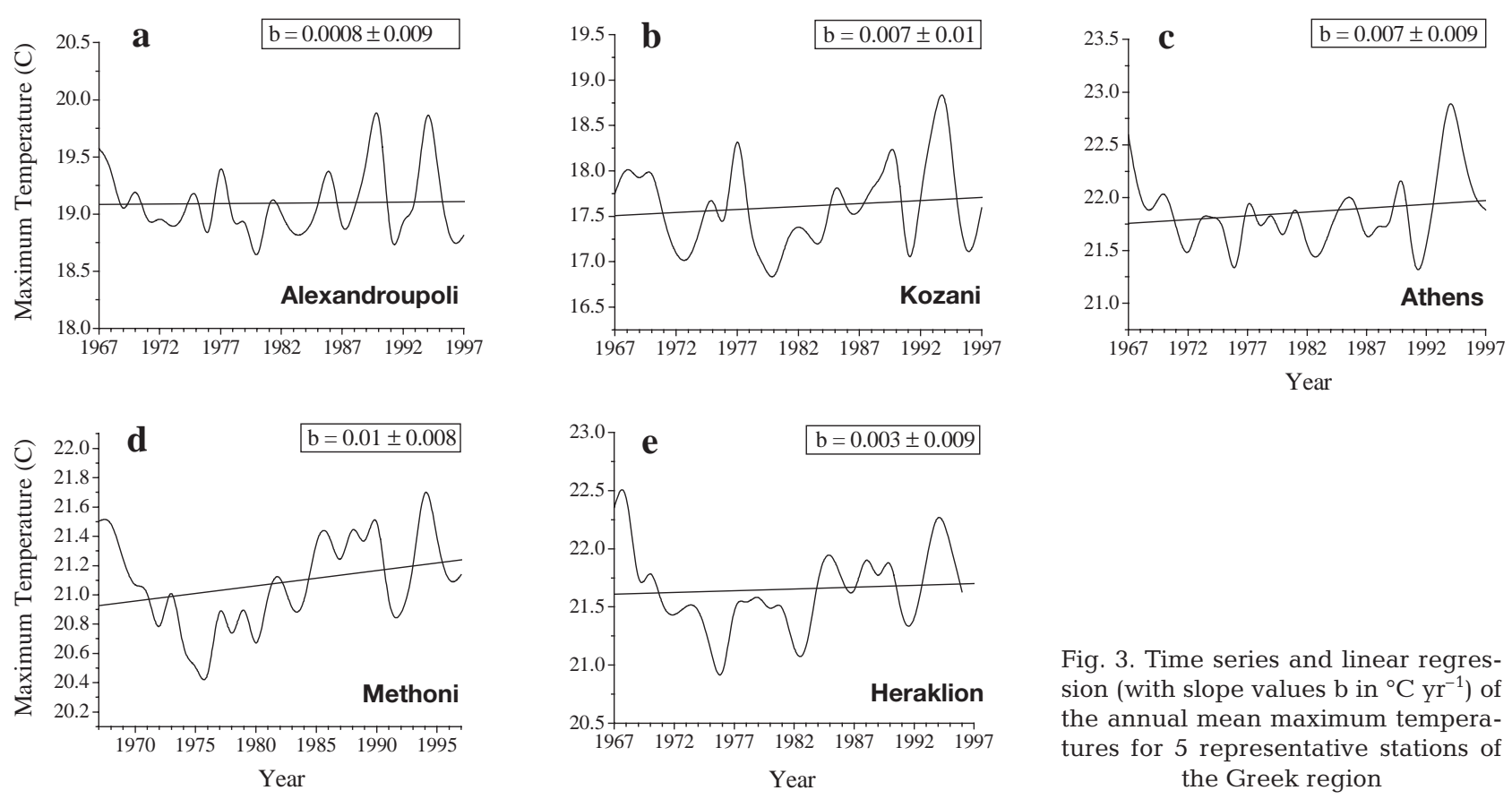

Fig. 3. Time series and linear regression (with slope values $\mathrm{b}$ in ${ }^{\circ} \mathrm{C} \mathrm{yr}^{-1}$ ) of the annual mean maximum temperatures for 5 representative stations of the Greek region

the slope value is different from zero (95\% significance level). In most cases, the slope was positive. Results for 5 representative stations are given in Fig. 3, showing a clear increase for Methoni, and small increases at Alexandroupoli, Kozani, Athens and Heraklion.

The parameters of Fourier Analysis for the 5 stations are shown in Table 1 . The values of $\bar{D}_{(t)}$ vary between 17.38 and $22.85^{\circ} \mathrm{C}$. Kozani, a semi-mountainous station (627 $\mathrm{m}$ altitude) in NW Greece, has the lowest value, and Athens in the SE, subject to strong urbanisation effects, has the highest value. In general, summer mean daily maximum temperatures are higher in southern than in northern Greece. The range of $\bar{D}_{(t)}$ values is about $5.5^{\circ} \mathrm{C}$. The semiamplitude A ranges between 7.7 and $11.2^{\circ} \mathrm{C}$, whereas the phase-angle $\varphi$ remains equal to about 1 . The range of daily maximum temperatures is narrower at the southern (Heraklion, Methoni and Athens) than at the northern stations, partly due to the influence of the sea. With regard to $\varphi$, which is related to seasonality, i.e. the calendar date on which the highest daily maximum temperature is

Table 1. Values of half width range A, phase angle $\varphi$, and annual mean expected daily maximum temperatures $\bar{D}_{(t)}$ (Eq. 1) at 5 representative Greek stations

\begin{tabular}{|lrcc|}
\hline Stations & $\mathrm{A}$ & $\varphi$ & $\bar{D}_{(t)}$ \\
\hline Alexandroupoli & 11.21 & 1.18 & 19.03 \\
Kozani & 10.96 & 1.23 & 17.38 \\
Athens & 9.30 & 1.06 & 22.85 \\
Methoni & 7.73 & 0.88 & 20.87 \\
Heraklion & 7.79 & 1.21 & 20.41 \\
\hline
\end{tabular}

expected, southern stations (Athens and Methoni) are characterised by earlier events than the northern ones (Kozani and Alexandroupoli).

In Fig. 4, the fluctuations of the observed and expected daily maximum temperatures, $D(t)$, are shown together with the temperature cut-off level, $U(t)$, for the warm period of 1991, which is shown as an example. The same procedure was applied to all stations for every year. The hot spells for the study period were derived from $T(t)$ and $U(t)$. In Fig. 4, the modified cut-off levels, $U^{\prime}(t)$, are also given, derived by adding $10^{\circ} \mathrm{C}$ to $D(t)$, as explained in Section 3.1. The number of hot spells for 1991 associated with $U^{\prime}(t)$ is larger than that derived by using $U(t)$ for the northern stations of Alexandroupoli and Kozani, while it is smaller at Athens, Methoni and Heraklion. In the northern areas (Alexandroupoli and Kozani), the hot spells appear mainly from the mid of June to the end of September. In the SE coastal station of Athens, hot spells are observed mainly in July and August, in the SW station of Methoni between 15 July and 15 August, while on Crete (Heraklion) they occur from the end of June until mid- and late July, for $U(t)$ and $U^{\prime}(t)$, respectively. On the Aegean Islands, hot spells are seldom observed from mid-July to the end of August, probably because of the persistent flow of Etesian (northerly) winds during this period (Meteorological Office 1962, Reiter 1975); here, hot spells occur mostly in early and in late summer.

The recorded number of hot spells was fitted by applying the Poisson distribution (Eq. 9 in Pappas et al. 2004), since it represents a series of rare random events. Fig. 5 shows the distributions of hot spells and 

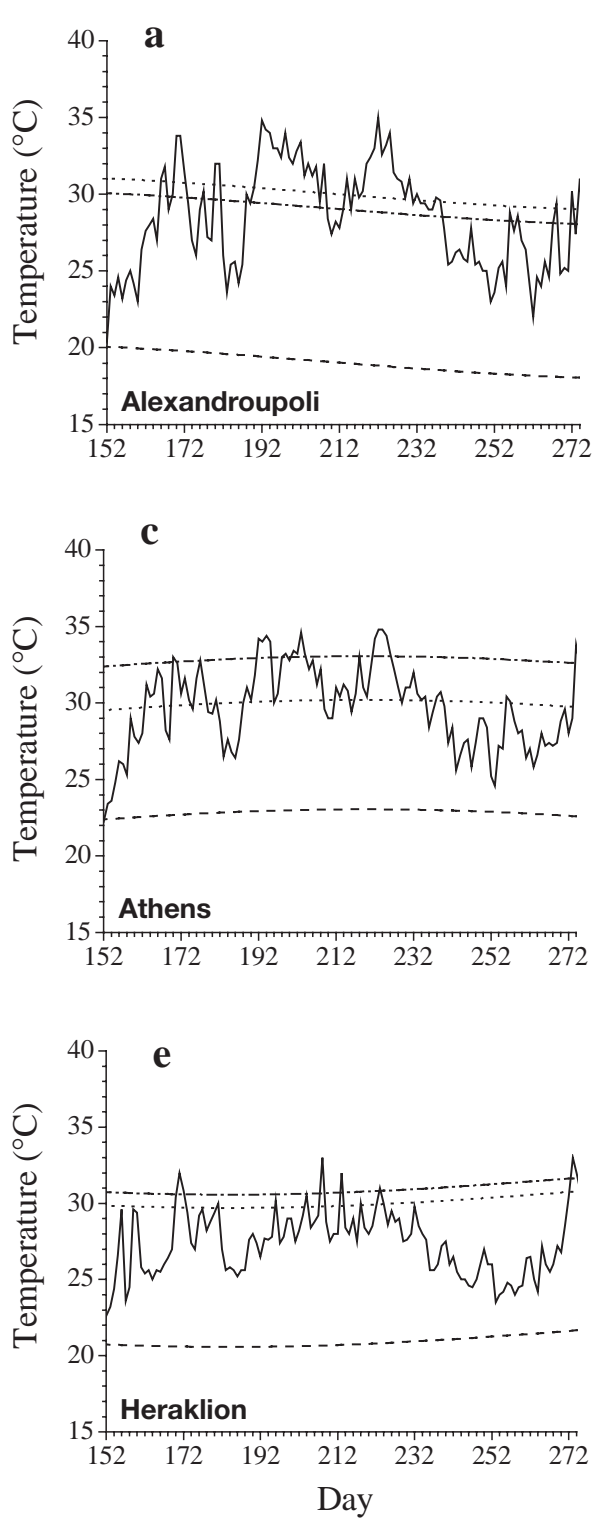

the corresponding Poisson distributions for cut-off levels $U(t)$ (left) and $U^{\prime}(t)$ (right), together with the parameter $\Lambda$, the mean number of hot spells within the study period (i.e. June to September). The mean number of hot spells at the 5 selected stations varies between about 4 and 11, depending on the area and the truncation level, with the highest frequencies at Alexandroupoli, Kozani and Athens, and the lowest at Methoni. The mean number derived by using $U^{\prime}(t)$, is lower, compared to that obtained with $U(t)$, for Kozani, Athens, Methoni and Heraklion, while it remains almost the same for Alexandroupoli. These features are very well reproduced by the Poisson distributions for all stations, with decreasing $\Lambda$ values, close to the observed ones, when using the cut-off level $U^{\prime}(t)$ instead of $U(t)$.
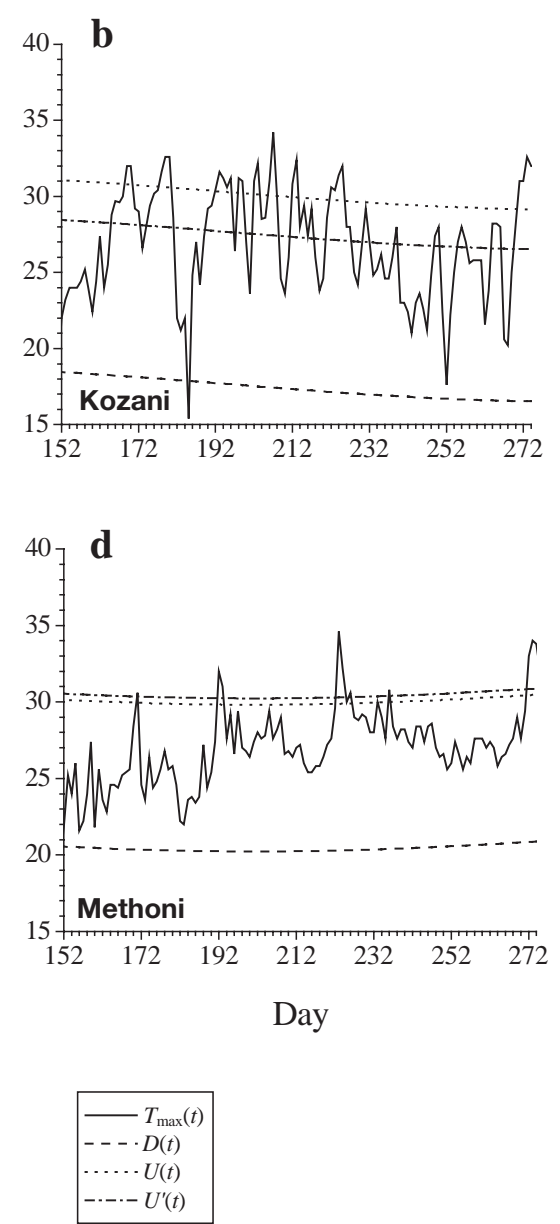

Fig. 4. Fluctuation of observed mean daily maximum temperature $T_{\max }(t)$ for 5 representative Greek stations for the period of June to September 1991. The expected daily maximum temperature $(D(t)$, see Eq. 1), and the temperature cut-off levels $U(t)$ and $U^{\prime}(t)$ are also shown

The $\chi^{2}$ goodness-of-fit test provided a good agreement between the theoretical and real distributions, both showing a gradual southward decrease of the probability of occurrence of hot spells, ranging from 9-11 for the northern and NE areas, to 4-9 hot spells in the southern and SW areas.

The potential period during which hot spells occur was achieved by applying the cumulative Gauss distribution (see Eq. 3). Fig. 6 shows the probability of timing of hot spells and the values of $\mu$ and $\sigma^{2}$. In all cases, the Gauss distribution provides a satisfactory fit to the observed timing of hot spells. The largest deviation was found for Methoni. Mean dates of the events for the 5 selected stations vary between 24 June and 1 July, having a standard deviation of up to $3 \mathrm{~d}$, approximately, depending on the area and the chosen 


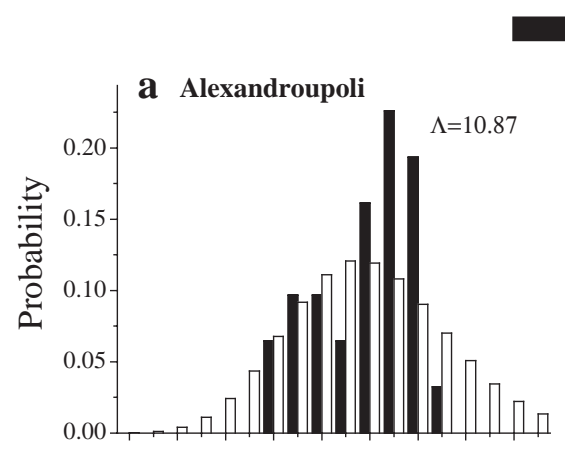

Observed $\square$ Poisson
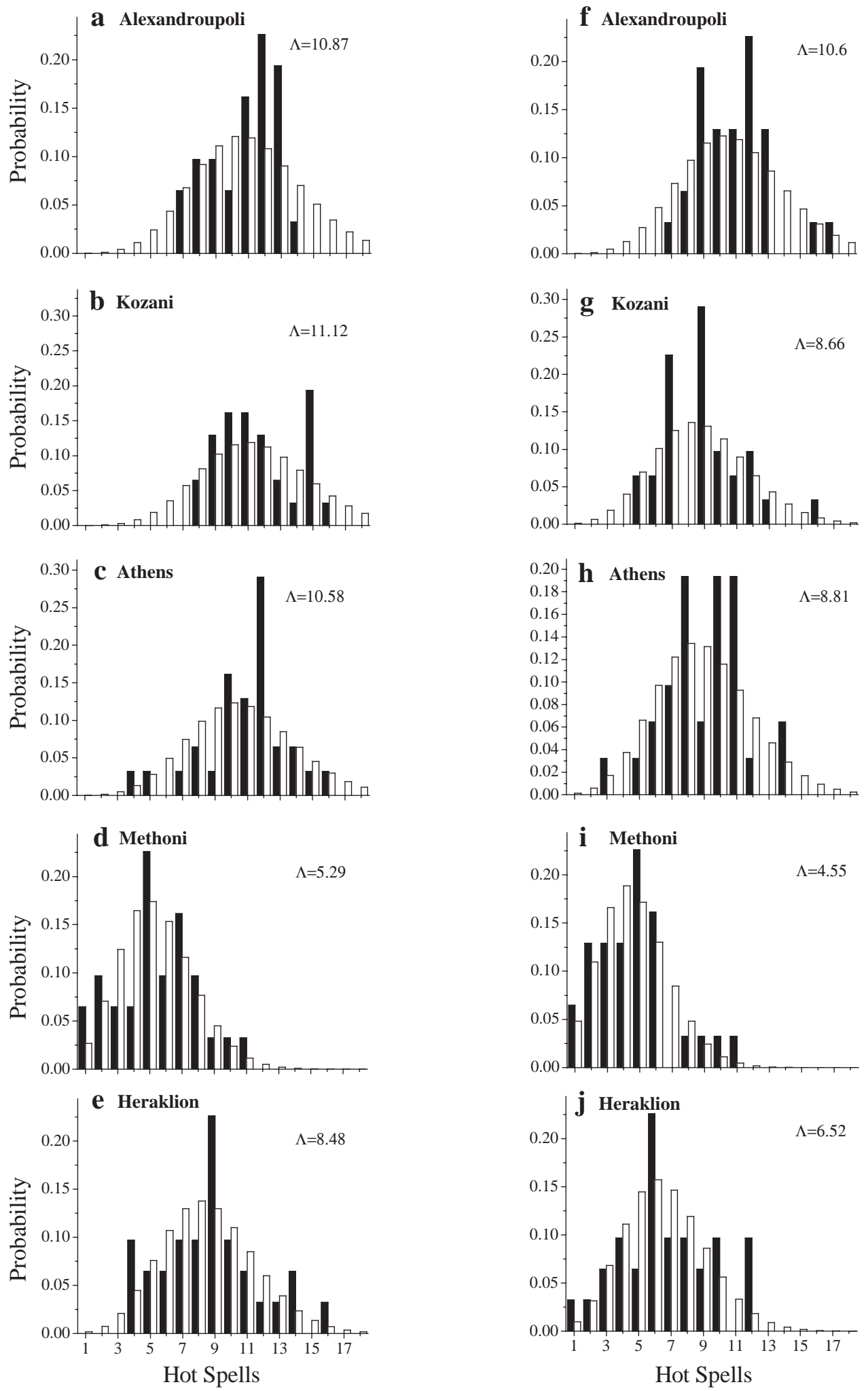

Fig. 5. (a-e) Probability distribution of the observed number of hot spells and the corresponding theoretical Poisson distribution by using temperature cut-off level $U(t)$ at 5 representative Greek stations. (f-j) Corresponding distributions computed by using the cut-off level $U^{\prime}(t)$ instead of $U(t)$. $\Lambda$ is the mean number of hot spells from the Poisson distribution 
- Observed a Gauss
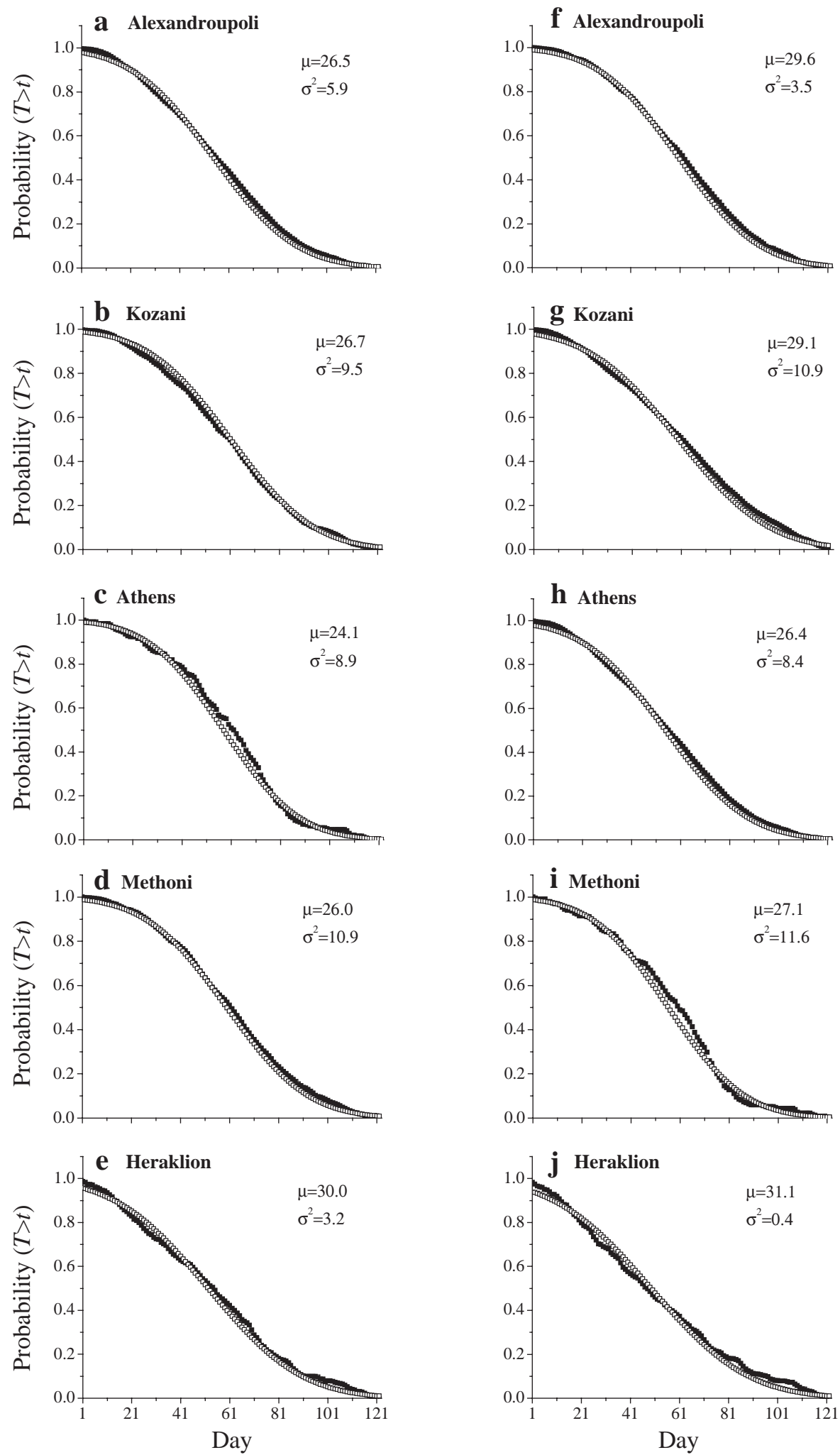

Fig. 6. Observed and fitted cumulative Gauss probability distributions of the timing of hot spells at 5 representative Greek stations. Left and right columns as in Fig. 5. The mean timing of hot spells $(\mu)$ and the variance $\left(\sigma^{2}\right)$ are also given 
cut-off level. The Gauss distribution shows a good agreement with the observed timing of hot spells (at the $95 \%$ significance level). The fit of the Gauss distribution is better for Athens when using the cut-off level $U^{\prime}(t)$ instead of $U(t)$, while it is slightly poorer for the southern station of Methoni. The application of the cutoff level $U^{\prime}(t)$, instead of $U(t)$, resulted in delayed hot spells by about 1 to $3 \mathrm{~d}$.

The estimated mean magnitude of hot spells (see Eq. 12 in Pappas et al. 2004) are shown in Fig. 7, where the observed magnitude is compared with the fitted exponential distribution. In general, the exponential distribution provides a good agreement with the computed distribution of magnitude of hot spells above the truncation level. Fig. 7 also shows the parameter $\gamma$ (mean magnitude of hot spells), which ranges from 1.5 to $3.6^{\circ} \mathrm{C}$. The most intensive hot-spell events were at Heraklion (Crete) and at the continental station of Kozani, where mean daily maximum temperatures are 2 to $3^{\circ} \mathrm{C}$ higher than normal, irrespective of the cut-off level. The less intensive hot spells $\left(\gamma=1.5^{\circ} \mathrm{C}\right)$ are found at Methoni, while intermediate values $\left(\gamma=2{ }^{\circ} \mathrm{C}\right)$ are found at Alexandroupoli and Athens. The $\chi^{2}$ test for the exponential distribution reveals a good agreement. A better agreement with the observed $\gamma$ values is obtained by using the cut-off level $U^{\prime}(t)$ instead of $U(t)$ for Alexandroupoli and Methoni, while the agreement for Heraklion is better with $U(t)$.

Table 2 gives the computed mean values of frequency, timing, and magnitude of hot spells. The spatial distribution of the mean number of hot spells strongly depends on the land/sea surface, with lower values on the Aegean Islands and higher at inland areas. Maximum frequencies occur in the central, northern and southern areas, as well as over the western mainland plains, and minimum frequencies occur over Aegean Sea. The moderating effect of the sea on summer maximum temperature is illustrated by the fact that stations on the coast experience less hot spells than continental stations of the same latitude (e.g. Limnos vs Larissa). The mean frequency of hot spells is highest in the southern and central parts, but only inland, at locations sheltered from sea breezes. This is particularly the case in the central Peloponnese and in Thessaly, where the mean monthly maximum temperatures attain 30 to $32^{\circ} \mathrm{C}$ and temperature maxima sometimes approach $45^{\circ} \mathrm{C}$, leading to uncomfortable conditions in the afternoon on cloudless days. The opposite occurs in the narrow coastal belt of the Greek Peninsula and in the Aegean Islands. Near the coast, even if the afternoon temperatures may rise well above $35^{\circ} \mathrm{C}$, the heat is relieved at the time of the afternoon maximum by refreshing sea breezes. In semi-mountainous areas (e.g. Kozani, Tripoli and Ioannina), the absolute maxima in frequency of hot spells are relatively high (10 to
11 events). Another feature of hot spells is their high frequency at Heraklion (Crete) and particularily on Rhodes Island. The frequent episodes of hot spells on the southern islands are associated with warm southerly winds, which bring warm continental-tropical (cT) air from Africa. This is consistent with the classification of synoptic weather types (see next section). Although the Aegean and Ionian Seas are relatively warm during the summer, they are cooler than the inland areas, and there is no convective activity. This is particularly the case along the coasts and over the Aegean Islands, where steady Etesian winds blow from the northern quadrant. These winds are due to the displacement of the Azores High towards NW Europe and to the low pressure which develops over the Iranian and Anatolian plateaus. At the same time, warm Foehn winds from the west and SW are intensified by the sloped ground causing subsidence of dry and warm airmasses in the interior land areas, increasing thus the intensity and probability of hot spell events in central and northern sectors of the Greek region, more frequently between the early and mid summer.

The mean time of occurrence of hot spells varies between 24 June and 1 July, with a variance ranging from 3 to $57 \mathrm{~d}$. The mean intensity varies between 1.5 and $3^{\circ} \mathrm{C}$, with the highest values found at Larissa and Serres $\left(3^{\circ} \mathrm{C}\right)$, and Thessaloniki $\left(2.8^{\circ} \mathrm{C}\right)$, Tripoli $\left(2.6^{\circ} \mathrm{C}\right)$ and Athens $\left(2.4^{\circ} \mathrm{C}\right)$, i.e. at inland stations, except for the large coastal cities of Athens and Thessaloniki (which experience urbanisation effects). Investigation of the role of physico-geographical parameters (latitude, longitude and altitude) for the frequency, timing and intensity of hot spells, through the application of linear regression analysis, did not show statistically significant results. Therefore, it is difficult to find any correlation between features of hot spells and relevant physico-geographical parameters. Consequently, for the interpretation of features of hot spells in the Greek region, it will be necessary to account for combinations of parameters such as latitude, longitude and altitude, with others, such as the downslope of the surface and the orientation of the region relative to the weather synoptic summer conditions.

\section{SYNOPTIC CONDITIONS FAVOURING HOT SPELLS}

Variability of weather conditions during the warm period is a distinct aspect of the NE Mediterranean and SE Europe. The Aegean and Ionian islands and the Greek peninsula are situated at latitudes that are close to the centre of the subtropical belt of high pressure in summer. Since these regions lie on the northern side of the high pressure belt, westerly winds predominate. 
- Observed ฉ Gauss
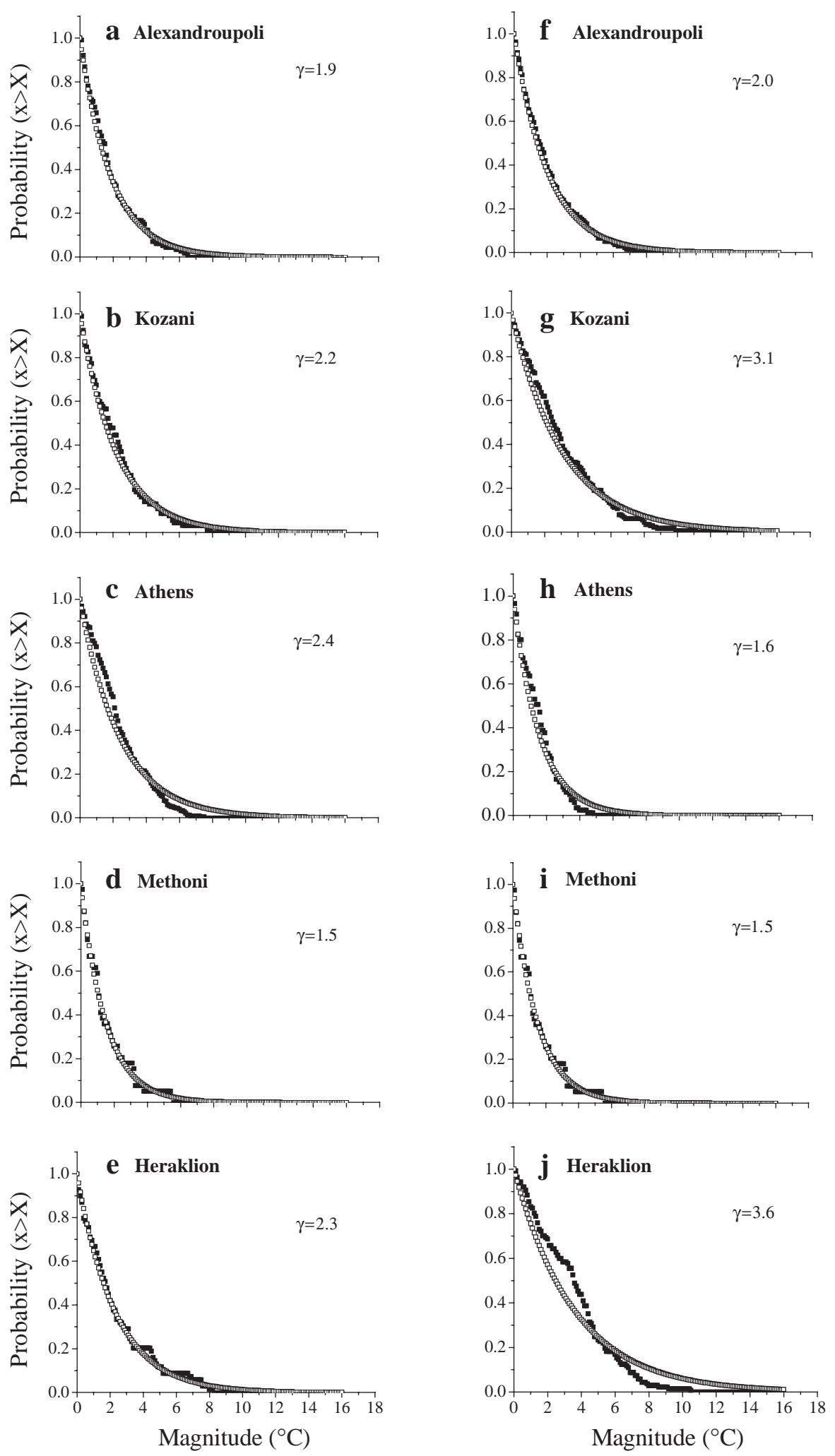

Fig. 7. Probability distribution of the observed magnitude of hot spells and the corresponding fitting exponential distribution at 5 representative Greek stations. Left and right columns as in Fig. 5. The value of the mean magnitude of hot spells ( $\gamma$ ) is also given 
Table 2. Values of computed mean number $(\Lambda)$, mean time $(\mu, d)$, variance of mean time $\left(\sigma^{2}\right)$ and mean magnitude $\left(\gamma^{\circ}{ }^{\circ} \mathrm{C}\right)$ of hot-spell events at 16 stations of the Hellenic National Meteorological Service (HNMS). Values in parenthesis were computed by using temperature cut-off level $U^{\prime}(t)$ instead of $U(t)$

\begin{tabular}{|lclll|}
\hline Stations & \multicolumn{1}{c}{$\Lambda$} & \multicolumn{1}{c}{$\mu$} & \multicolumn{1}{c}{$\sigma^{2}$} & \multicolumn{1}{c}{$\gamma$} \\
\hline Athens & $10.6(8.8)$ & $24.1(26.4)$ & $8.9(8.4)$ & $2.4(1.6)$ \\
Thessaloniki & 9.1 & 27.5 & 7.5 & 2.8 \\
Ioannina & $9.6(4.3)$ & $26.7(28.2)$ & $12.2(11.2)$ & $1.9(2.0)$ \\
Methoni & $5.3(4.5)$ & $26.0(27.1)$ & $10.9(11.6)$ & $1.5(1.5)$ \\
Araxos & 11.0 & 26.7 & 53.9 & 2.3 \\
Tripoli & 11.1 & 29.7 & 56.6 & 2.6 \\
Kozani & $11.1(8.7)$ & $26.7(29.1)$ & $9.5(10.9)$ & $2.2(3.1)$ \\
Larissa & 11.1 & 30.4 & 56.5 & 3.0 \\
Kavala & 4.3 & 26.4 & 12.2 & 1.5 \\
Alexandroupoli & $10.9(10.6)$ & $26.5(29.6)$ & $5.9(3.5)$ & $1.9(2.0)$ \\
Serres & 9.7 & 30.0 & 8.4 & 3.0 \\
Limnos & 6.6 & 23.8 & 45.7 & 1.3 \\
Rhodes & 11.3 & 26.5 & 51.4 & 1.6 \\
Naxos & 4.9 & 27.9 & 50.9 & 1.5 \\
Heraklion & $8.5(6.5)$ & $30.0(31.1)$ & $3.2(0.4)$ & $2.3(3.6)$ \\
Kithira & 7.8 & 23.6 & 48.4 & 1.7 \\
& & & & \\
\hline
\end{tabular}

Nevertheless, the frequency and strength of these westerlies have their minima at the warm period of the year. By June, the region is dominated by the extension of the subsident air mass of the Azores anticyclone, causing westerly flow; this flow is also associated with the extension of the thermal low over the eastern Mediterranean (Palutikof et al. 1996, Katsoulis et al. 1998). Thermal lows usually form over the Balkans and Greece during this warm period. The persistence of these synoptic conditions leads to long periods of hot and dry spells (Xoplaki et al. 2003). Summer conditions are also influenced by advective and convective processes exerted by local atmospheric mesoscale circulation, which constitute a critical factor controlling regional air temperature fluctuations and changes (e.g. Xoplaki et al. 2002).

In general, the air-flow over the region during the warm period is mainly influenced by: (1) an anticyclone located over central and SW Europe, resulting in northerly to NE air-flows over most of the Greek region (easterly weather type); (2) an anticyclone or a ridge of high pressure situated over most of the Mediterranean (blocking conditions), with prevailing westerly to NW flows (anticyclonic weather type); (3) a thermal low over the Iranian and Anatolian plateaus (Reiter 1975, Brody \& Nestor 1980).

Visual examination of the daily (12 UTC) surface and upper level weather charts from HNMS and the GMS during spells of consecutive hot days (with $T_{\max }>$ $30^{\circ} \mathrm{C}$ ), led to a first classification of the synoptic situations that favour the occurrence of hot spells in the region into 4 categories:
(A) An anticyclone (the Azores subtropical high) is located over North Africa. The displacement and extension of this highpressure system towards the east-northeast results in a westerly flow with a more northerly component over the region. A $700 \mathrm{hPa}$ high extends from North Africa to the Balkans, whereas a closed weak high develops at the $850 \mathrm{hPa}$ level above the NE Mediterranean and extends across Greece. These strong and persistent anticyclonic conditions cause flows of hot and subsiding dry African air masses across the Greek region, resulting in consecutive hot days.

(B) The Azores anticyclone extends towards western and central Europe. This extension is associated in most cases with a secondary high pressure system in the central and eastern Mediterranean and over the Balkans. In this case, hot spells appear with high frequency but low intensity, which is further moderated by the presence of low pressure in Asia Minor.

(C) A blocking anticyclone is situated over SW and/or western and central Europe. This is associated with the existence of a warm lower troposphere, resulting in subsidence and stability that advects warm and humid air masses over Greece and the Balkans. A weak high occurs over the Eastern Mediterranean troposphere, and extends over the Greek region. This ridge is shallow, since the $1000 / 500 \mathrm{hPa}$ thickness charts indicate that it is warm one with a mean thickness of $5800 \mathrm{~m}$. These stable atmospheric conditions produce clear skies and maximum irradiance over the region.

(D) An anticyclone (or a ridge of high pressure) is located over most of the Mediterranean Basin, associated with a weak thermal low over the Balkans. The sea is warm, but still cooler than the land, and there is no convective activity. Variable winds or SW and westerly flows prevail over the region.

The highest probability for a hot spell over the region exists during weather synoptic conditions of Category A $(42 \%)$, followed by Category B (30\%), when hot spells are usually short (2 to $3 \mathrm{~d})$, Category D (17\%) and, finally, Category C (11\%). Therefore, $72 \%$ of the hot spells are associated with the extensions of the Azores High or the anticyclones of western and/or central Europe (Categories A and B).

\section{CONCLUDING REMARKS}

In this study, a statistical analysis of hot spells occurring over the Greek region was performed. Our results 
show that daily maximum temperatures can be studied by deterministic and stochastic components, while the characteristics can be adequately described in terms of statistical distributions. The spatio-temporal characteristics of hot spells occurring over a complex area such as Greece were described by using a relatively complete data set.

The application of the model and the analysis of hot spell characteristics for sample stations representative of the various sub-regions, led to the following conclusions:

(1) The hot spells identified in this study are mainly limited to early June through mid-July, and to the late summer (September). The interim period is influenced by Etesian winds.

(2) The spatial and temporal distribution is mostly related to local physico-geographic and synoptic characteristics. Hot spells are most frequent in southern parts of the inland area, at places sheltered from sea breezes. Conversely, hot spells are less frequent along the coastal belt of the Peninsula, and on the Aegean Islands, because of the moderating effect of the sea.

(3) The mean time of hot spells ranges from 24 June to 1 July, with a mean variance $\left(\sigma^{2}\right)$ of 3 to $57 \mathrm{~d}$.

(4) The mean intensity varies between about 1.5 and $3^{\circ} \mathrm{C}$, with higher values in continental areas, and lower values in coastal areas.

(5) The frequency, timing and magnitude are reproduced and represented satisfactorily by statistical distributions.

(6) The highest probability of hot spells exists when a persistent Azores anticyclone appears over North Africa and extends ridges of high pressure towards the region.

(7) The strongest hot spells are associated with an extension of high pressure into the region, subsidence and stability of the air mass, advection from the northeast in the mid- and upper troposphere and westerly air flow in the warm lower troposphere over the Balkans; it is also associated with increased sea surface temperatures and decreased frequency and intensity of northerly winds near the surface.

The method applied here may serve for describing hot spells in the near future, when a more complete data base will become available, by using data from a denser recording network with a larger temporal coverage (>30 yr). Moreover, the results of our analysis may be related to the increase in concentrations of trace gases and aerosols, which may occur in the regional atmosphere, changing the intensity and frequency of the synoptic patterns described.

Acknowledgements. The authors are grateful to the Hellenic National Meteorological Service for providing the daily temperature data.

\section{LITERATURE CITED}

Anagnostopoulou C, Maheras P, Karakostas T, Vafiadis M. (2003) Spatial and temporal analysis of dry spells in Greece. Theor Appl Climatol 74:77-91

Balling RC, Skindlov JA, Phillips DH (1990) The impact of increasing summer mean temperature on extreme maximum and minimum temperatures in Phoenix, Arizona. J Clim 3:1491-1494

Beniston M (2004) The 2003 heat wave in Europe: a shape of things to come? An analysis based on Swiss climatological data and model simulations. Geophys Res Lett 31(2):art. No L02202

Brody LR, Nestor MJR (1980) Handbook for forecasters in the Mediterranean, Part 2. Naval Environmental Prediction Research Facility, US Department of Commerce, Monterey, CA

Changnon D (1993) Variability in high temperature extremes in the southeastern United States. Phys Geogr 14:599-611

Changnon SA, Kunkel KE, Reike BC (1996) Impacts and responses to the 1995 heat wave: a call to action. Bull Am Meteorol Soc 77:1497-1506

Corte-Real J, Zhang X, Wang X (1995) Large-scale circulation regimes and surface climatic anomalies over the Mediterranean. Int J Climatol 15:1135-1150

Cramer H, Leadbetter MR (1967) Stationary and related stochastic processes. Wiley, New York

Degaetano AT (1996) Recent trends in maximum and minimum temperature threshold exceedences in the northeastern United States. J Clim 9:1646-1660

Domonkos P (1998) Statistical characteristics of extreme temperature anomaly groups in Hungary. Theor Appl Climatol 59:165-179

Domonkos P (2001) Temporal accumulations of extreme daily mean temperature anomalies. Theor Appl Climatol 68: $17-32$

Douguedroit A (1987) The variations of dry spells in Marseilles from 1865 to 1984. Int J Climatol 7:541-551

Easterling DR, Evans JL, Groisman PY, Karl TR, Kunkel KE, Ambenje P (2000) Observed variability and trends in extreme climate events: a brief review. Bull Am Meteorol Society 81:417-425

Flocas AA (1981) Persistence of cold and hot spells at Thessaloniki. Arch Meteorol Geophys Bioklimatol Ser A 30: 135-144

Flocas AA, Angouridakis V (1979) Extreme value analysis of air temperature over Greece. Arch Meteorol Geophys Bioklimatol B 27:47-57

Folland CK, Miller C, Bader D, Crowe M and 6 others (1999) Workshop on Indices and Indicators for Climate Extremes. Asheville, NC, USA, 3-6 June 1997, Breakout Group C: Temperature Indices for Climate Extremes. Clim Change 42:31-43

Furlan D (1977) The climate of Southeast Europe. In: Landsberg HE (ed) World survey of climatology. Elsevier, Amsterdam, p 185-220

Gerstengarbe FN, Werner FN (1992) The time structure of extreme summers in central Europe (1901-1980). Meteorol Z 1:285-289

Giles BD, Balafoutis CJ (1990) The Greek heat waves of 1987 and 1988. Int $\mathrm{J}$ Climatol 10:505-517

Giles BD, Balafoutis C, Maheras P (1990) Too hot for comfort: the heat waves in Greece in 1987 and 1988. Int J Biometeorol 34:98-104

Goossens C, Berger A (1984) Persistence of dry and wet spells in Belgium. Arch Meteorol Geophys Bioklimatol Ser B 34: $243-256$ 
Heino R, Bradzil R, Forland E, Tuomenvirta H and 7 others (1999) Progress in the study of climate extremes in northern and central Europe. Clim Change 42:151-181

Henderson KG, Muller RA (1997) Extreme temperature days in the south-central United States. Clim Res 8:151-162

Karl TR, Easterling DR (1999) Climate extremes: selected review and future research directions. Clim Change 42: 309-325

Karl TR, Knight WR (1997) The 1995 Chicago heat wave: how likely is a recurrence? Bull Am Meteorol Soc 78: 1107-1119

Katsoulis BD, Makrogiannis TJ, Goutsidou YA (1998) Monthly anticyclonicity in southern Europe and the Mediterranean region. Theor Appl Climatol 59:51-59

Katsoulis BD (1987) Indications of change of climate from the analysis of air temperature time-series in Athens, Greece. Clim Change 10:67-79

Katsouyanni K, Trichopoulos D, Zavitsanos X, Touloumi G (1988) The 1987 Athens heat wave. Lancet 2(8610):573

Katz RW, Brown BG (1992) Extreme events in a changing climate: variability is more important than averages. Clim Change 21:289-302

Leboutillier DW, Waylen PR (1988) Stochastic analysis of cold spells. J Appl Meteorol 27:67-76

Macchiato M, Serio C, Lapenna VL, La Rotonda L (1993) Parametric time-series analysis of cold and hot spells in daily temperature: an application in southern Italy. J Appl Meteorol 32:1270-1281

Maheras P, Xoplaki E, Davis E, Martin-Vide J, Bariendos J, Alcoforado MJ (1999) Warm and cold monthly anomalies across the Mediterranean basin and their relationship with circulation: 1860-1990. Int J Climatol 19:1697-1715

Matzarakis A, Mayer H (1991) The extreme heat wave in Athens in July 1987 from the point of view of human biometeorology. Atmos Environ Part B 25:203-211

Matzarakis A, Mayer H (1997) Heat stress in Greece. Int J Biometeorol 41:34-39

McCarthy JJ, Canziani OF, Leary NA, Dokken DJ, White KS (eds) (2001) Climate change 2001: impacts, adaptation, and vulnerability. Intergovernmental Panel on Climate Change (IPCC), Cambridge University Press, New York

Mearns LO, Katz RW, Schneider RW (1984) Extreme hightemperature events: Changes in their probabilities with

Editorial responsibility: Helmut Mayer,

Freiburg, Germany changes in mean temperature. J Clim Appl Meteorol 23: 1601-1613

Meteorological Office (1962) Weather in the Mediterranean. HMSO, London

Palutikof JP, Conte M, Casimiro Mendes J, Goodess CM, Espirito Santo F (1996) Climate and Climatic Change. In: Brandt CJ, Thomas JB (eds) Mediterranean desertification and land use. J Wiley \& Sons, London, p 43-86

Pappas C, Hatzianastassiou N, Katsoulis BD (2004) Analysis of cold spells in the Greek region. Clim Res 27:211-223

Reiter ER (1975) Handbook for forecasters in the Mediterranean: weather phenomena of the Mediterranean Basin, Part 1. Tech Pap 5-75, Naval Postgraduate School, Monterey, CA

Repapis C (1975) On the hot invasions to the higher troposphere in Greece. PhD thesis, University of Ioannina, Greece (in Greek)

Robinson PJ (2001) On the definition of heat waves. J Appl Meteorol 40:762-775

Rohli RV, Keim BD (1994) Spatial and temporal characteristics of extreme high summer temperature events in the southcentral United States. Phys Geogr 15:310-324

Ross SM (1985) Introduction to probability models. Academic Press, Orlando

Wagner D (1999) Assessment of the probability of extreme weather events and their potential effects in large conurbations. Atmos Environ 33:4151-4155

WMO (World Meteorological Organisation) (1983) Guide to climatological practices. WMO Tech Note 111, World Meteorological Organisation, Geneva

WMO (1986) Guidelines on the quality control of surface climatological data. In: Abbot PF, Rapporteur in the WMO Commission for Climatology. World Climate Programme (WCP-85), IV, Appendices. World Meteorological Organisation, Geneva

Xoplaki E, Gonzalez-Rouco JF, Gyalistras D, Luterbacher J, Rickli R, Wanner H (2002) Interannual summer air temperature variability over Greece and its connection to the large-scale atmospheric circulation and Mediterranean SSTs 1950-1999. Clim Dyn 20:537-554

Xoplaki E, Gonzalez-Rouco JF, Luterbacher J, Wanner H (2003) Mediterranean summer air temperature variability and its connection to the large scale atmospheric circulation and SSTs. Clim Dyn 20:723-739

Submitted: February 1, 2005; Accepted: March 21, 2005

Proofs received from author(s): May 12, 2005 